Full length article

\title{
Cracks, porosity and microstructure of Ti modified polymer-derived SiOC revealed by absorption-, XRD- and XRF-contrast 2D and 3D imaging
}

\author{
Małgorzata Makowska a, Pradeep Vallachira Warriam Sasikumarc, Lorenz Hagelüken ${ }^{\mathrm{d}}$, \\ Dario F. Sanchez ${ }^{e}$, Nicola Casati ${ }^{e}$, Federica Marone ${ }^{e}$, Gurdial Blugan ${ }^{c}$, Jürgen Brugger ${ }^{d}$, \\ Helena Van Swygenhoven ${ }^{\mathrm{a}, \mathrm{b}, *}$
}

a Photons for Engineering and Manufacturing, Paul Scherrer Institute, Villigen, PSI CH-5232, Switzerland

${ }^{\mathrm{b}}$ Neutrons and $x$-rays for mechanics of materials, École Polytechnique Fédérale de Lausanne (EPFL), Lausanne CH-1015, Switzerland

${ }^{c}$ Laboratory of High Performance Ceramics, EMPA, Dübendorf $\mathrm{CH}-8600$, Switzerland

d Microsystems Laboratory, École Polytechnique Fédérale de Lausanne (EPFL), Lausanne CH-1015, Switzerland

e Swiss Light Source, Paul Scherrer Institute, Villigen, PSI CH-5232, Switzerland

\section{A R T I C L E I N F O}

\section{Article history:}

Received 14 May 2020

Revised 27 July 2020

Accepted 29 July 2020

Available online 1 August 2020

Keywords:

Polymer derived ceramics

Ti modified SiOC

Tomographic microscopy

Chemical imaging

Diffraction contrast imaging

\begin{abstract}
A B S T R A C T
Morphology, phase composition, cracks and porosity are investigated in monolithic Ti modified SiOC polymer-derived ceramics pyrolyzed at $1000{ }^{\circ} \mathrm{C}$ and $1400{ }^{\circ} \mathrm{C}$ using synchrotron X-ray full field absorptioncontrast tomographic microscopy and scanning XRF- and XRD-contrast microscopy. Samples pyrolyzed at $1000{ }^{\circ} \mathrm{C}$ show a crack-free structure, but pyrolysis at $1400{ }^{\circ} \mathrm{C}$ results in formation of cracks and at higher Ti content also shows porosity. Tomography revealed the formation of a layered morphology that varies in terms of crystallographic structure and/or Ti stoichiometric concentration. The microstructural observations and electrical conductivity are discussed in terms of pyrolysis temperature and Ti content.
\end{abstract}

(C) 2020 Acta Materialia Inc. Published by Elsevier Ltd.

This is an open access article under the CC BY license. (http://creativecommons.org/licenses/by/4.0/)

\section{Introduction}

Polymer-derived ceramics (PDCs) [1,2] are promising candidates in a broad field of applications [3,4], for instance as protective coatings [5], fiber-reinforced ceramic-matrix composites [6], insulators, electrodes in Li-ion batteries [7-10] or catalytic supports for hydrogen generation [11]. The use of liquid precursors allows for manufacturing of micron-scale ceramic components with high precision by micromolding $[12,13]$ or lithography based techniques [14-16]. Recently, it was shown that two-photon polymerization (TPP) can be applied for the manufacturing of PDCs with complex geometries and sub-micron level precision [17-20]. Such advanced manufacturing technologies could be used to produce microparts for microelectromechanical systems (MEMS).

The pyrolysis temperature plays a key role in determining PDC material structure and properties [13,21]. For instance, the electrical conductivity, an important parameter in the design of implantable devices for stimulation, such as pacemaker electrodes, in-

\footnotetext{
* Corresponding author.

E-mail address: helena.vs@psi.ch (H. Van Swygenhoven).
}

creases significantly in $\mathrm{SiOC}$ with increase of pyrolysis temperature from $1000{ }^{\circ} \mathrm{C}$ to $1400{ }^{\circ} \mathrm{C}$. However, pyrolysis at higher temperatures leads to severe cracking and warping of monolithic samples produced by molding techniques [13].

Modification of PDCs by adding metal-precursors in the starting polymer can be used to tune the structure and properties of PDCs. For instance, Ti- modified SiOC shows a higher electrical conductivity after pyrolysis at $1000{ }^{\circ} \mathrm{C}$ [22]. The amount of Ti precursor added to the starting polymer mixture also affects mechanical properties such as flexural strength. The samples with highest investigated Ti content had lower flexural strength but large standard deviation and seemed to be frequently inhomogeneous in structure [22].

Crystallization process of SiCO has been investigated previously by Raj et al. [23].This work explains chemical mechanisms of decomposition at temperatures below $1350{ }^{\circ} \mathrm{C}$ leading to $\beta$-SiC formation in different temperature regions. Comprehensive studies of the crystallization process of polymer-derived SiOC ceramic as a function of time and temperature were presented by Poerschke et al. [21]. The authors investigated crystallization of single particles within ceramic matrix composites samples annealed at 
temperatures up to $1500{ }^{\circ} \mathrm{C}$. According to their work [21], the first step of crystallization of SiOC PDCs is the chemical decomposition of the amorphous phase, which occurs at the pores and cracks connected to the surface and longer annealing results in the translation of the reaction front towards inner parts of the particles, suggesting that pyrolysis of monolithic samples can result in significant gradients of crystalline phases from the surface towards the bulk.

The main expected crystalline phase after crystallization of polymer-derived SiOC ceramic is $\beta$-SiC $[1,4,21,24,25]$. When Ti is added, the crystallization process is more complex and three phases are expected: $\mathrm{TiC}$, TiO (both in rock salt structure, space group Fm3-m) and $\beta$-SiC (zinc blende, space group F-43 m), as it was shown in $[26,27]$. It is well known that the isostructural compounds $\mathrm{TiC}$ and $\mathrm{TiO}$ can form a solid solution $\mathrm{TiO}_{1-\mathrm{x}} \mathrm{C}_{\mathrm{x}}$ [28-33]. TiC - SiC systems can create solid solution either in zinc blende, or in rock salt structure [34-36].

Due to expected spatial inhomogeneities, understanding the structure of Ti modified polymer-derived SiOC requires the use of spatially resolved techniques, such as tomography. X-ray tomography was for instance applied in studies of fiber-reinforced ceramicmatrix composites to reveal the evolution of matrix structure and crack development during pyrolysis [6] and to investigate the connection between void distribution, local fiber bed porosity and impregnation conditions [37]. In this work, we present spatially resolved structural studies of Ti modified polymer-derived SiOC ceramic samples produced by the molding technique. Synchrotron tomographic microscopy is used to map the cracks, porosity and phases, while the crystallographic structure and elemental composition of the features observed in tomograms are further addressed by local XRD- and XRF-contrast microscopy. The combination of these techniques gives a unique possibility to understand the distribution of crystallographic phases with spatial resolution of $1 \mu \mathrm{m}$ in PDC samples of millimeter size and to directly link the distribution of the phases to the sample morphology and the distribution of defects such as cracks. The analysis of these results is supported by in-situ powder diffraction measurements providing an integrated signal for larger volumes and shrinkage analysis performed by Thermomechanical Analysis (TMA).

\section{Experimental}

\subsection{Material synthesis}

Polymethylhydrosiloxane (MW $\approx 1900$, PHMS, Sigma Aldrich), divinyl benzene (DVB, technical grade, 80\%, Sigma Aldrich), Titanium(IV) ethoxide (TiOET, Sigma Aldrich) and platinum Karstedt's catalyst (platinum(0)-1,3-divinyl-1,1,3,3-tetramethyldisiloxane complex solution in xylene, $\mathrm{Pt} \approx 2 \%$, Sigma-Aldrich) have been used as main constituents using the synthesis procedure reported previously $[13,22]$. In a typical procedure, the platinum Karstedt's catalyst $(5 \mu \mathrm{L})$ is added to a mixture of PHMS (1.25 g)/DVB $(2.5 \mathrm{~g}) /$ TiOET (X wt\%, $X=10,20,30$ and 40 ). The mixture was stirred at room temperature for $30 \mathrm{~min}$. Subsequently, the preceramic mixture was cast in Teflon molds and left overnight at ambient conditions (room temperature, air atmosphere in a fume hood). The gelation was observed within $3 \mathrm{~h}$. Afterwards, discs of $7 \mathrm{~mm}$ diameter were cut from the solid preceramic films and the preceramic polymer discs were then aged in a drying oven at $80{ }^{\circ} \mathrm{C}$ for $48 \mathrm{~h}$, followed by pyrolysis in an alumina tubular furnace (Carbolite STF 16/450, Germany) under flowing argon atmosphere at $1000{ }^{\circ} \mathrm{C}$ or $1400{ }^{\circ} \mathrm{C}$ with a holding time of $1 \mathrm{~h}$ at the target temperature. After pyrolysis, which is accompanied with shrinkage, samples had a diameter of about $5 \mathrm{~mm}$ and thickness ranging between $200 \mu \mathrm{m}$ and $400 \mu \mathrm{m}$. According to the amount of TiOET (X) added to the precursor formulation, final pyrolyzed samples are further referred to as SiTiOCX (SiTiOC10, SiTiOC20, SiTiOC30, SiTiOC40).

The contents of $\mathrm{Ti}, \mathrm{C}$ and $\mathrm{O}$ in the SiTiOC samples (discs crushed into powders) were determined by elemental analysis performed by the company Mikroanalytisches Labor Pascher (Remagen-Bandorf, Germany). The content of Si was estimated as the difference between the total amount of all elements (100 wt\%) and the sum of $\mathrm{O}, \mathrm{C}$, and Ti contents (in wt\%).

\subsection{Sample preparation for absorption-, XRF- and XRD-contrast imaging studies}

Preliminary tomographic experiments have shown the presence of inhomogeneities appearing uniformly around the radial and circumferential directions, but varying with the thickness. Therefore, cross sections of discs were investigated. Depth-resolved XRF- and XRD- contrast microscopy analysis of such cross sections were conducted. Because of the low (X-ray) energies of the Ti- $\mathrm{K}_{\alpha}$ emission lines which are highly attenuated by the sample itself (attenuation length in the order of 30 to $50 \mu \mathrm{m}$, depending on the compositional and porosity levels), $50 \mu \mathrm{m}$ thick and about $100 \mu \mathrm{m}$ long lamellae were cut out from these discs using Xe-ion plasma FIB-SEM Tescan Fera3 at the ScopeM (Scientific center for electron and optical Microscopy, ETH Zürich). The height of the lamellae was equal to the disk thickness. The same samples were used for measurements at microXAS and TOMCAT beamlines of the Swiss Light Source (SLS) at Paul Scherrer Institute (PSI). Dimensions of lamellae were optimized for XRD-/ XRF-contrast microscopy (at microXAS), but they were kept on bigger parts of discs, as illustrated in Fig. 1a). Therefore, the samples were still large enough to provide statistically significant information of the structure of whole discs, when investigated by absorption contrast tomographic microscopy.

\subsection{Full field tomographic microscopy}

X-ray absorption contrast tomographic microscopy at the TOMCAT beamline (SLS, PSI) [38] was performed to visualize the internal structure of the samples. In principle, contrast obtained with this method is related to the density of material. In case of the investigated SiTiOC samples, different grayscales can thus be related to different elemental distributions (in particular $\mathrm{Ti}$ ) or different atomic arrangements determining packing density of atoms. Tomographic microscopy was conducted using a detector setup composed of a $100 \mu \mathrm{m}$-thick LuAG:Ce scintillator, an optical microscope with 10x magnification and a sCMOS camera. These settings result in a field of view (FOV) of $1.66 \mathrm{~mm} \times 1.40 \mathrm{~mm}$ with $0.65 \mu \mathrm{m}$ pixel size. 1501 projections were acquired over $180^{\circ}$ with $120 \mathrm{~ms}$ exposure time per projection. Additionally, 10 dark current images and 100 flat field images (open beam) were acquired for normalization of the images. An X-ray beam energy of $15 \mathrm{keV}$ was used. The tomographic volumes were reconstructed from the acquired $X$ ray projections using the tomographic reconstruction pipeline implemented at TOMCAT [39] based on the gridrec algorithm [40]. $3 \mathrm{D}$ visualization of the reconstructed volumes as well as segmentation of the materials was performed using Avizo Thermo Fischer Software [41].

\subsection{Mapping of Ti distribution and crystallographic phases by XRF- and XRD-contrast microscopy}

The distribution of the Ti atoms and crystallographic phases in the samples was obtained by X-ray fluorescence (XRF) and diffraction (XRD) contrast microscopy performed at the microXAS beamline (SLS, PSI) [42]. The lamellae of the PDC samples were mounted 
a)

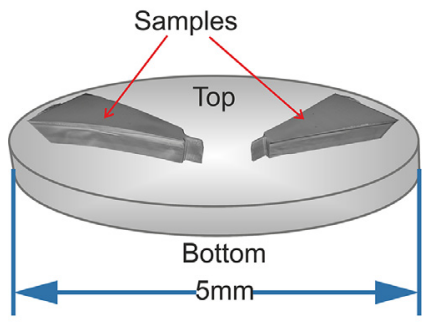

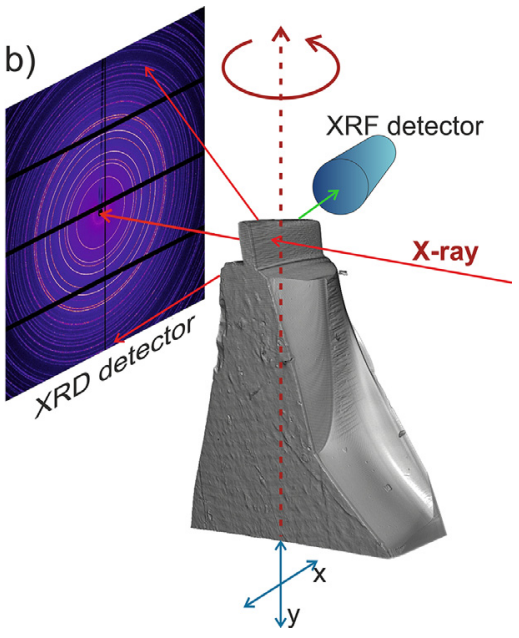

Fig. 1. Schematics of a) samples cut from PDC discs for XRD-/ XRF- contrast microscopy, b) setup for the XRD-/ XRF-contrast microscopy experiments.

on the sample manipulator with a high precision air-bearing rotational stage at the beamline as illustrated in Fig. 1. For each sample, two types of measurements were performed:

- "Projection mode": 2D scanning over an area covering the full height of lamellae (x direction in Fig. 1) and width (y in Fig. 1) of about $50-100 \mu \mathrm{m}$ by translating the sample over $\mathrm{x}$ and $\mathrm{y}$ directions (Fig. 1). This mode provides 2D maps of Ti and crystallographic phase distributions integrated over the thickness of the lamellae.

- "Computed-tomography mode": 1 slice tomography performed by scanning the samples in $\mathrm{x}$ direction (Fig. 1) in a continuous manner, at different orientations equally spaced over $180^{\circ}$ to visualize Ti distribution over cross sections of the lamellae.

In both cases, the fluorescence and diffraction signals were recorded simultaneously, as well as the incoming and transmitted intensity at each sample position, with a dwell time of $200 \mathrm{~ms}$. The $\mathrm{X}$-ray beam was focused down to $1 \times 1 \mu^{2}$ using Kirkpatrick-Baez (KB) mirrors, which also defines the limit of the spatial resolution. The XRF signal was recorded using two silicon drift detectors (SDDs), diffraction patterns were measured with a 2D Eiger4M area detector, the transmitted intensity with a mini SiC diode mounted in the beamstopper and the incoming beam with a mini ionization chamber mounted in the exit window KB box (maintained under helium atmosphere). The measurements were done with an X-ray beam energy of $14.7 \mathrm{keV}$, which corresponds to a wavelength of $0.84343 \AA$ A. The relative positions of XRD detector - sample - Xray beam direction were calibrated based on measurement of a $\mathrm{LaB}_{6}$ standard from NIST. It should be noted that one sample pyrolyzed at $1000{ }^{\circ} \mathrm{C}$ was measured using an X-ray beam at energy of $17.2 \mathrm{keV}$, which corresponds to a wavelength of $0.7208 \AA$. More information about the measurement method can be found in [43].

20 different PDC samples were investigated with synchrotron full field tomography. Since XRD- and XRF-contrast microscopy is conducted in scanning manner, it requires significantly longer measurement time (about $3 \mathrm{~h}$ per one scan in contrast to several min needed for tomography), as well as complex sample preparation. Therefore, only 8 selected samples were measured at the microXAS beamline.

\subsection{Time resolved powder diffraction}

Powder diffraction (PD) measurements were performed at the Material Science (MS) beamline of the SLS [44] in order to investigate the dynamics of the crystallization process in Ti modified
SiOC ceramics. In-situ experiments were limited to one intermediate sample SiTiOC20 (20 wt\% of Ti precursor TiOET in the starting polymer mixture). Time-resolved PD measurements were performed using the Mythen microstrip detector [45] with the X-ray beam energy set to $22 \mathrm{keV}$. The wavelength evaluated using a $\mathrm{LaB}_{6}$ standard was $0.5638 \AA$. Prior to the in-situ test and using the same setup, two disk-shaped SiTiOC20 samples sintered in advance at temperatures of $1000{ }^{\circ} \mathrm{C}$ and $1400{ }^{\circ} \mathrm{C}$ were measured as a reference. For in-situ studies, a $0.8 \mathrm{~mm}$ thin and $10 \mathrm{~mm}$ long specimen was cut out from the green body and placed in a single crystal sapphire capillary. Samples were pyrolyzed using a graphite resistance furnace, custom-designed for use at the MS beamline, with $5{ }^{\circ} \mathrm{C} / \mathrm{min}$ rate up to $1100{ }^{\circ} \mathrm{C}$. At this temperature the first measurements were acquired. This was followed by fast heating in steps of $100{ }^{\circ} \mathrm{C}\left(100{ }^{\circ} \mathrm{C}\right.$ increase was reached in less than $\left.30 \mathrm{~s}\right)$ and with holding times of $30 \mathrm{~min}$ at each step. Diffraction patterns were acquired every $3 \mathrm{~min}$ at $1200{ }^{\circ} \mathrm{C}, 1300{ }^{\circ} \mathrm{C}$ and $1400{ }^{\circ} \mathrm{C}$. Analysis of the acquired powder diffraction data was performed using TOPAS Bruker AXS software [46].

\subsection{Electrical properties of samples and thermomechanical analysis}

Room temperature DC electrical conductivity of the pyrolyzed ceramic discs was measured using a Keithley 2450 source meter (Textronix UK, Ltd., Berkshire, UK) connected with a four point collinear probe set up. Shrinkage analysis was carried out by means of thermomechanical analysis (TMA) using a NETZSCH TMA analyzer (TMA 402F3, NETZSCH-Gerätebau $\mathrm{GmbH}$ ) in the temperature range of $20-1500{ }^{\circ} \mathrm{C}$ with a heating/cooling rate of $5{ }^{\circ} \mathrm{C} / \mathrm{min}$ and a load of $0.1 \mathrm{~N}$ applied along the sample height. Samples for TMA were prepared in a cylindrical shape with dimensions of $5 \mathrm{~mm}$ diameter and $4 \mathrm{~mm}$ height.

\section{Results}

\subsection{Elemental composition of final PDC samples}

The elemental Si, C, O and $\mathrm{Ti}$ content of selected samples is summarized in Table 1 . The Ti content after pyrolysis is approx. $10 \mathrm{wt} \%$ for SiTiOC20 (20 wt\% TiOET in the starting precursor) and $20 \mathrm{wt} \%$ for SiTiOC40 composition (40 wt\% of TiOET in the starting precursor). The Ti content of samples SiTiOC20 does not depend on the pyrolysis temperature. However, a reduction in carbon and oxygen content is observed at $1400{ }^{\circ} \mathrm{C}$, which is due to the gas evolution of $\mathrm{CO}$ and $\mathrm{CO}_{2}$ at higher pyrolysis temperatures. In the 

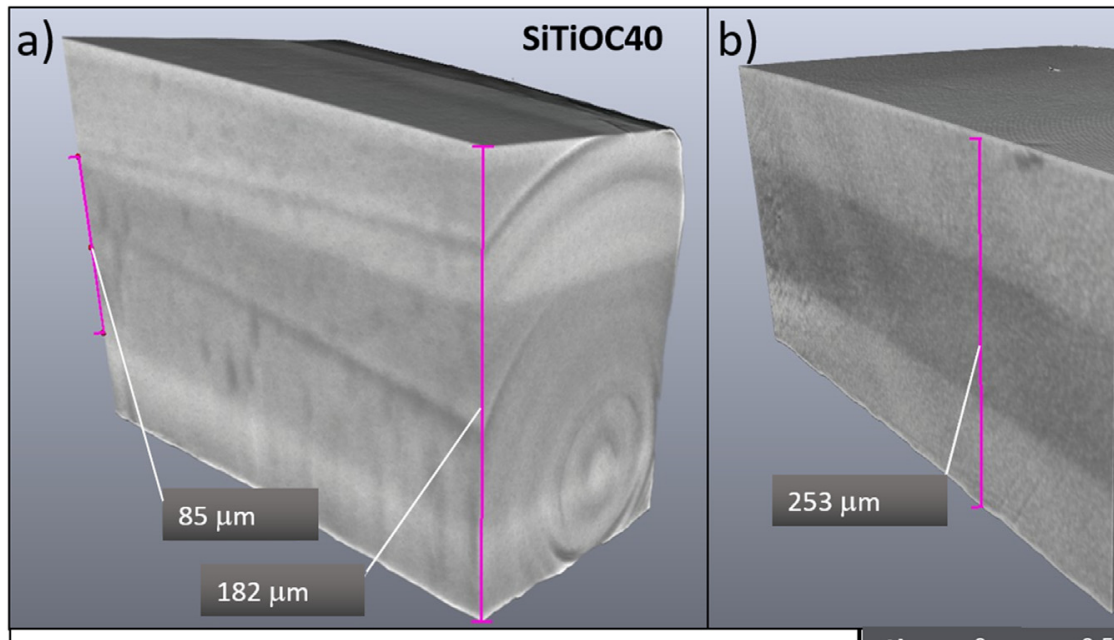

SiTiOC20
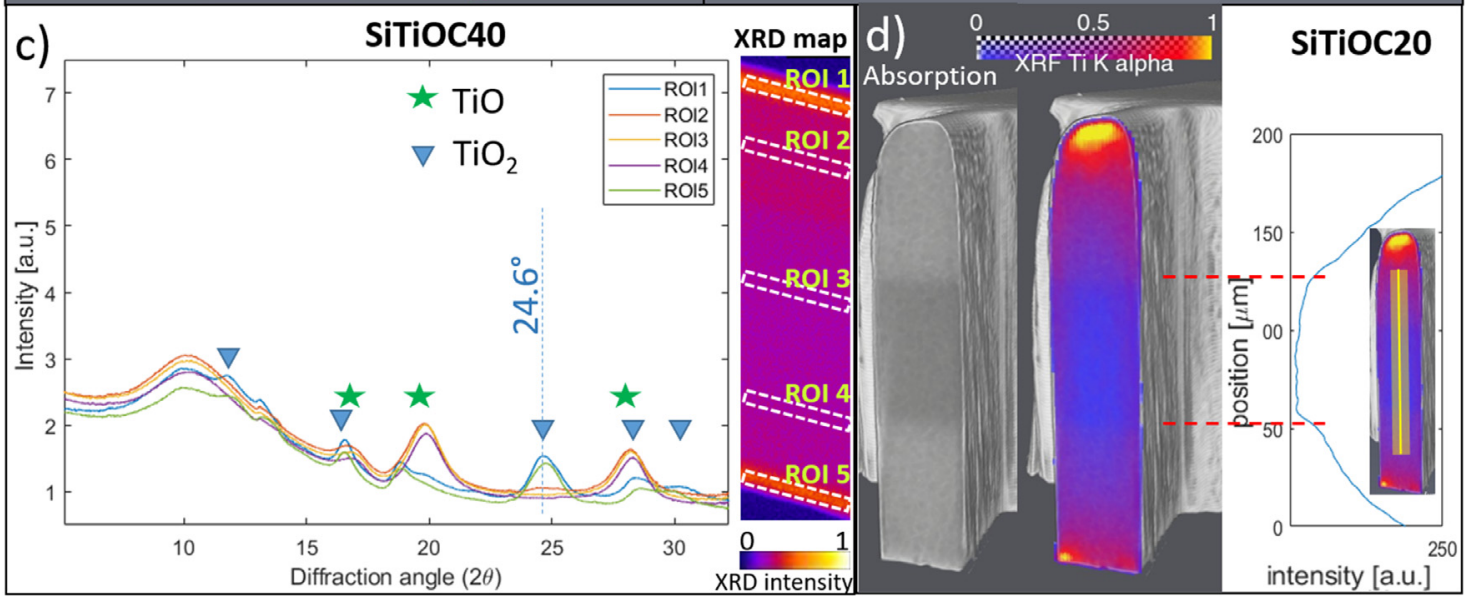

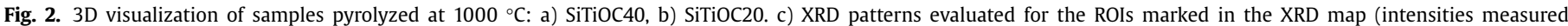

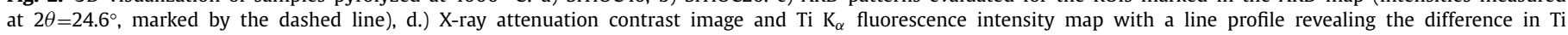

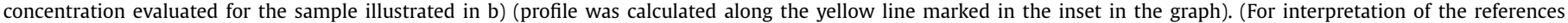
to colour in this figure legend, the reader is referred to the web version of this article.)

Table 1

Elemental compositions of $\mathrm{Si}, \mathrm{Ti}, \mathrm{O}$ and $\mathrm{C}$ and empirical formulae of final ceramics.

\begin{tabular}{|c|c|c|c|c|c|}
\hline \multirow[b]{2}{*}{ Sample name } & \multicolumn{4}{|c|}{ Elemental content (wt\%) } & \multirow[b]{2}{*}{ Empirical formula } \\
\hline & $\mathrm{Si}$ & $\mathrm{C}$ & 0 & $\mathrm{Ti}$ & \\
\hline $\operatorname{SiOC}\left(1000^{\circ} \mathrm{C}\right)$ (Ref) & - & - & - & - & $\mathrm{SiO}_{0.96} \mathrm{C}_{4.4}$ \\
\hline SiTiOC20 $\left(1000{ }^{\circ} \mathrm{C}\right)$ & 27.08 & 35.79 & 28.00 & 9.13 & $\mathrm{SiTi}_{0.2} \mathrm{O}_{1.81} \mathrm{C}_{3.08}$ \\
\hline SiTiOC20 $\left(1400{ }^{\circ} \mathrm{C}\right)$ & 30.06 & 32.14 & 27.40 & 10.40 & $\mathrm{SiTi}_{0.2} \mathrm{O}_{1.60} \mathrm{C}_{2.49}$ \\
\hline SiTiOC40 $\left(1000{ }^{\circ} \mathrm{C}\right)$ & 20.96 & 28.54 & 30.00 & 20.50 & $\mathrm{SiTi}_{0.57} \mathrm{O}_{2.5} \mathrm{C}_{3.18}$ \\
\hline
\end{tabular}

case of SiTiOC40, a significantly higher $\mathrm{O} / \mathrm{Si}$ ratio of 1.5 is observed and the source of higher oxygen content is from the Ti precursor.

\subsection{Synchrotron absorption-contrast tomographic microscopy combined with chemical and crystallographic mapping performed by $X R D$ - and XRF-contrast microscopy}

Tomography studies conducted at the TOMCAT beamline of SiOC:Ti samples with different amounts of added Ti and pyrolyzed at $1000{ }^{\circ} \mathrm{C}$ or at $1400{ }^{\circ} \mathrm{C}$ reveal various types of inhomogeneities in the volume, which is described in detail in the following sections.

\subsubsection{Samples SiTiOC20-40 pyrolyzed at $1000{ }^{\circ} \mathrm{C}$}

Absorption contrast tomographic microscopy shows that pyrolysis at $1000{ }^{\circ} \mathrm{C}$ leads to the formation of a layered structure in the SiTiOC40 and SiTiOC20 samples, as shown in Fig. 2a) and b), respectively. The samples are crack and pore-free and no deformation such as warping is observed.

Fig. 2c) shows the diffraction patterns recorded in regions of interest (ROI) marked in the XRD map (measured in the "projection mode") in Fig. 2c), integrated across the thickness of the SiTiOC40 sample. In all regions, an amorphous phase characterized by the broad peak at $2 \theta=10^{\circ}$ can be distinguished. Furthermore, a few peaks corresponding to nanocrystalline $\mathrm{TiO}$ are observed for regions selected away from the surface (ROI 2, 3, 4). In the vicinity of the surface (ROI 1,5 ) a few other peaks are observed, the position and shape of which correspond to nanocrystalline rutile $\mathrm{TiO}_{2}$ phase.

The regions showing variations in the XRD patterns (Fig. 2c) however, do not correspond with the layered structure observed in absorption contrast tomography. The contrast between the layers can be explained by X-ray fluorescence based mapping. Fig. 2d) presents a Ti $\mathrm{K}_{\alpha}$ fluorescence intensity map and intensity line profile performed on the cross section of a lamella cut out from the SiTiOC20 sample shown in Fig. 2b). The two red lines drawn on the line profile indicate the change step in the line profile corresponding to the Ti concentration change. The marked positions correspond well also to the change in contrast seen in the tomography image (Fig. 2b)). It is therefore clear that lower Ti content, which gives lower X-ray attenuation coefficient, can be assigned to the darker layer in the image reconstructed from absorption contrast tomography. 


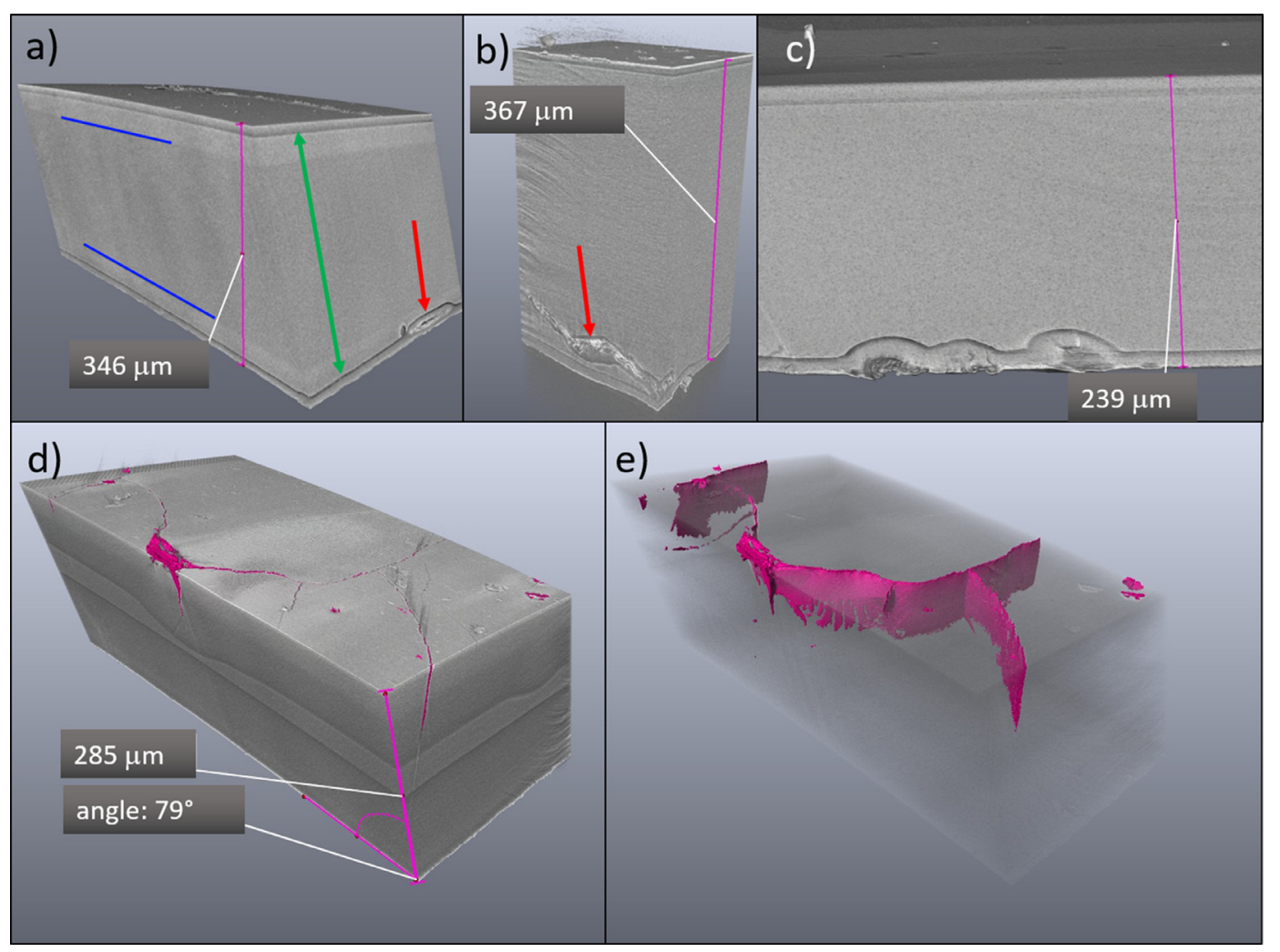

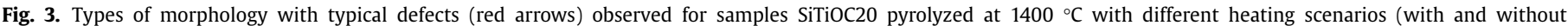

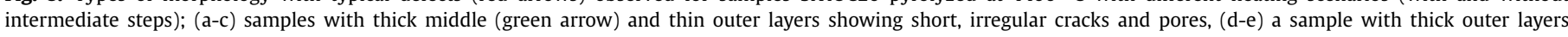

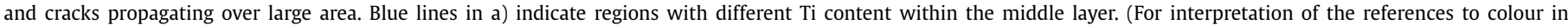
this figure legend, the reader is referred to the web version of this article.)

Note, that the XRF map was reconstructed from measurements done in tomography mode. Fluorescence radiation has a significantly lower energy than the incoming beam and therefore this map is strongly affected by the absorption of XRF radiation within the sample. The measured intensity depends on the distance from the probed voxel to the surface of the sample towards the detector and thus, the voxels closer to the surface appear brighter than those closer to the sample center. Such effect is commonly known as "cupping" artifact, as it results in "cup"-shaped line profiles (Fig. 2d)). The line profile evaluated for Ti XRF map plotted in Fig. 2c) is a superposition of the profile reflecting Ti concentration and a cup-shaped line caused by absorption of $\mathrm{Ti} \mathrm{K}_{\alpha}$ fluorescence. Nevertheless, the clear steps in the profile marked by the red lines can be explained only by a change of Ti content. Due to the cupping artefacts this change cannot be quantified. The full field tomography suggest however that Ti content is homogeneous within the particular layers.

\subsubsection{Samples SiTiOC20 pyrolyzed at $1400{ }^{\circ} \mathrm{C}$}

Pyrolysis at $1400{ }^{\circ} \mathrm{C}$ of SiTiOC20 samples changes their structure and morphology as compared with $1000{ }^{\circ} \mathrm{C}$. Fig. 3 shows several samples obtained with different annealing sequences: (a) and (b) by heating directly to the target temperature and holding $1 \mathrm{~h}$ at $1400{ }^{\circ} \mathrm{C}$; (c) by holding the sample sequentially $1 \mathrm{~h}$ at $1000{ }^{\circ} \mathrm{C}$, $1 \mathrm{~h}$ at $1200{ }^{\circ} \mathrm{C}$ and $1 \mathrm{~h}$ at $1400{ }^{\circ} \mathrm{C}$. Interestingly, no clear differences were observed in the structure and morphology between the samples pyrolyzed at $1400{ }^{\circ} \mathrm{C}$ for $1 \mathrm{~h}$ or sequentially exposed to $1000{ }^{\circ} \mathrm{C}, 1200{ }^{\circ} \mathrm{C}$ and $1400{ }^{\circ} \mathrm{C} 1 \mathrm{~h}$ each in the performed measurements. All samples are composed of a thick and relatively homogeneous middle layer (marked with the green line in Fig. 3a)) and two thin layers close to the surface. The outer layers are further referred to as bottom and top layers, correspondingly to the sample orientation during pyrolysis. In the bottom layer, relatively short and irregular cracks or flat pores are detected. Some cracks propagated inward, but are surrounded by the same phase as found in the bottom layer. Such morphology was observed in the majority of the investigated samples, regardless of heating scenarios during pyrolysis. In two cases however, a different morphology with clearly thicker outer layers was obtained, as shown in Fig. 3d) and e). In these samples, more severe cracks that spread over a significantly larger volume are detected. Fig. 3d) shows that the cracks in the bottom layer propagated over the entire length and width of the sample. However, they appeared only within one layer, but did not through the middle layer and outer top layer.

The observed defects can be related to the difference in structure of the layers. Fig. 4 shows XRF- and XRD-contrast microscopy performed for the sample presented in Fig. 3a) (pyrolyzed with holding $1 \mathrm{~h}$ at $1400{ }^{\circ} \mathrm{C}$ ). XRF mapping (Fig. 4a) reveals several regions with respect to the Ti distribution. The highest concentration of $\mathrm{Ti}$ is observed in the outer layers, but also within the middle layer the regions closer to the outer layers have higher Ti content than the most center region (between the blue lines in Fig. 3a)). These regions correspond well with the slight intensity variations in tomographic images (regions separated by blue lines in Fig. 3a)).

XRD-contrast microscopy shows significant difference in crystallographic structure of the top, middle and bottom layers of the sample. Fig. 4e) presents the XRD patterns integrated over ROIs marked in Fig. 4d). The three main phases identified in these patterns are titanium oxycarbide $\mathrm{TiO}_{1-\mathrm{x}} \mathrm{C}_{\mathrm{x}}$, silicon carbide $\beta$-SiC and amorphous $\mathrm{SiOC}$ (around $2 \theta=11.5^{\circ}$ ). The diffraction peaks observed for the ROIs selected in the middle layer (ROI3, ROI4, ROI5) correspond mostly to nanocrystalline $\mathrm{TiO}_{1-\mathrm{x}} \mathrm{C}_{\mathrm{x}}$ phase, but the amorphous phase is also present. The outer layers are composed of $\mathrm{TiO}_{1-\mathrm{x}} \mathrm{C}_{\mathrm{x}}$ and $\beta$-SiC. The $\mathrm{TiO}_{1-\mathrm{x}} \mathrm{C}_{\mathrm{x}}$ peaks measured in ROI1, ROI2, 

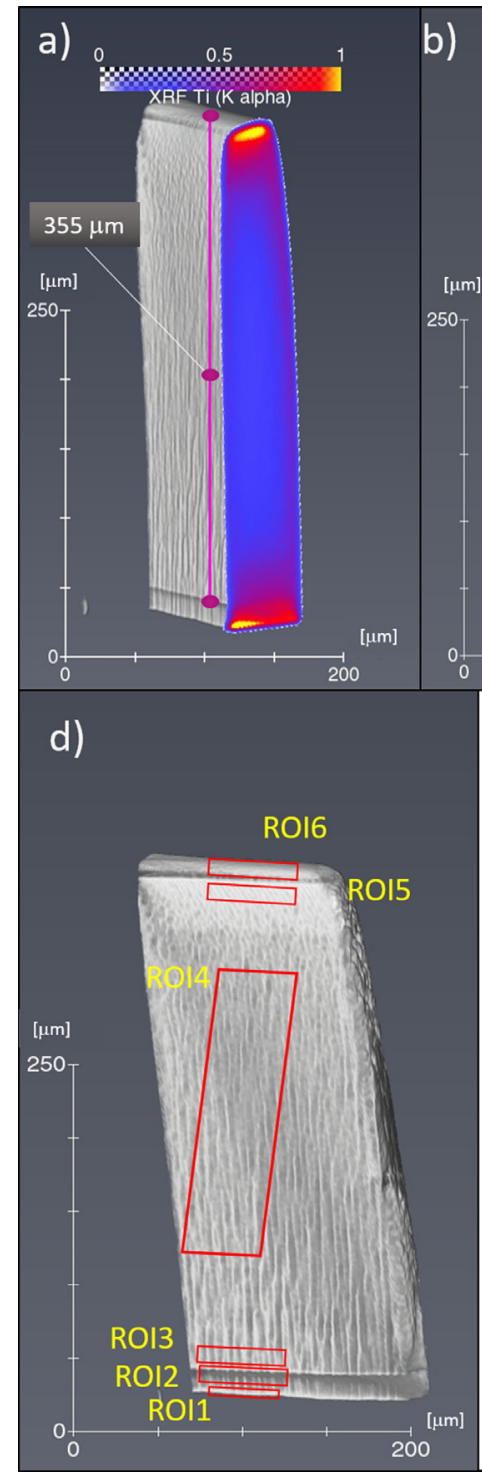

b)

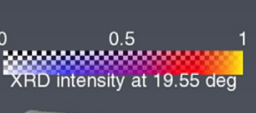

c)

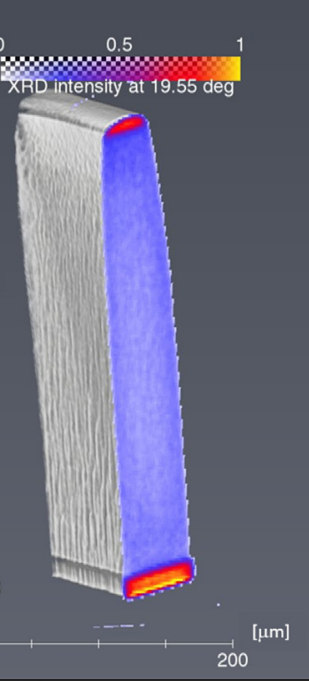

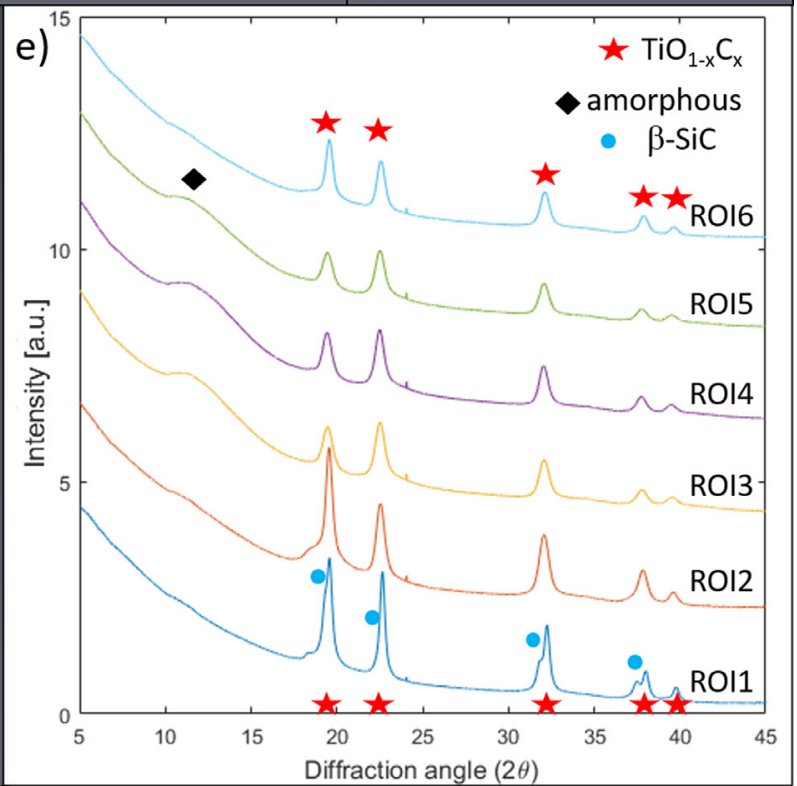

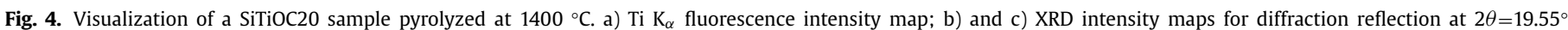

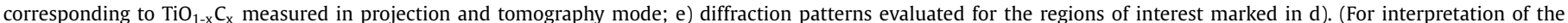
references to colour in this figure legend, the reader is referred to the web version of this article.)

ROI6 have significantly lower FWHM, suggesting larger crystallites. The diffraction patterns taken from the bottom layer show the largest amount of $\beta$-SiC phase and the closer to the surface, the more distinct separation of the peaks corresponding to $\beta$-SiC and $\mathrm{TiO}_{1-\mathrm{x}} \mathrm{C}_{\mathrm{x}}$ phases is observed. Note that small shoulders can be observed on the left hand side of the overlapping peaks of $\beta$-SiC and $\mathrm{TiO}_{1-\mathrm{x}} \mathrm{C}_{\mathrm{x}}$ of the outer layers. This may be explained by presence of $\beta$-SiC stacking faults, as described in literature $[21,47,48]$. These shoulders are not visible in patterns of the middle layer, where the amorphous phase is still present and no $\beta$-SiC phase is observed.

Fig. 4b) and c) present maps of diffraction intensity measured at $2 \theta=19.55^{\circ}$, which visualizes the distribution of $\mathrm{TiO}_{1-\mathrm{x}} \mathrm{C}_{\mathrm{x}}$ phase measured in "projection" and "tomography mode". These maps show that the middle layer has a very homogeneous structure in terms of crystallographic phases. There is however a gradient in phase composition between the middle layer and the outer layers. Moreover, there is a strong phase gradient within the bottom layer itself, where the defects were also observed (Fig. 3a, b, c).

The samples with a thicker outer layer (Fig. 3d), showed analogous results: their middle layers consist of nanocrystalline $\mathrm{TiO}_{1-\mathrm{x}} \mathrm{C}_{\mathrm{x}}$ and amorphous SiOC and the outer layers of $\beta$-SiC and $\mathrm{TiO}_{1-\mathrm{x}} \mathrm{C}_{\mathrm{x}}$. $\mathrm{XRF}$ and XRD mapping results for the sample with thick outer layers illustrated in Fig. 3d) are available in the supplementary materials (Fig. A).

\subsubsection{Samples SiTiOC30-40 pyrolyzed at $1400{ }^{\circ} \mathrm{C}$}

Pyrolysis at $1400{ }^{\circ} \mathrm{C}$ of PDC with higher content of Ti leads to significant porosity and more severe cracking, while keeping the layered structure. Fig. 5 and 6 show the results for a SiTiOC30 sample. Tomographic microscopy reveals homogeneously distributed spherical pores with an average diameter of $4 \mu \mathrm{m}$ (Fig. 5a), b)). This average diameter was evaluated using the label analysis function available in Avizo software. Due to the high contrast obtained between the pores and the bulk, material segmentation was performed using an intensity threshold based procedure. The total porosity evaluated by material segmentation was $4 \%$. As shown in Fig. 5a), the middle layer is completely free of cracks, while both outer layers have evidence of more cracking. Fig. 5c)-j) show the cracking in planes parallel to the surface layer, taken at different positions indicated by red dashed lines in Fig. 5a). Fig. 5g)-j) 


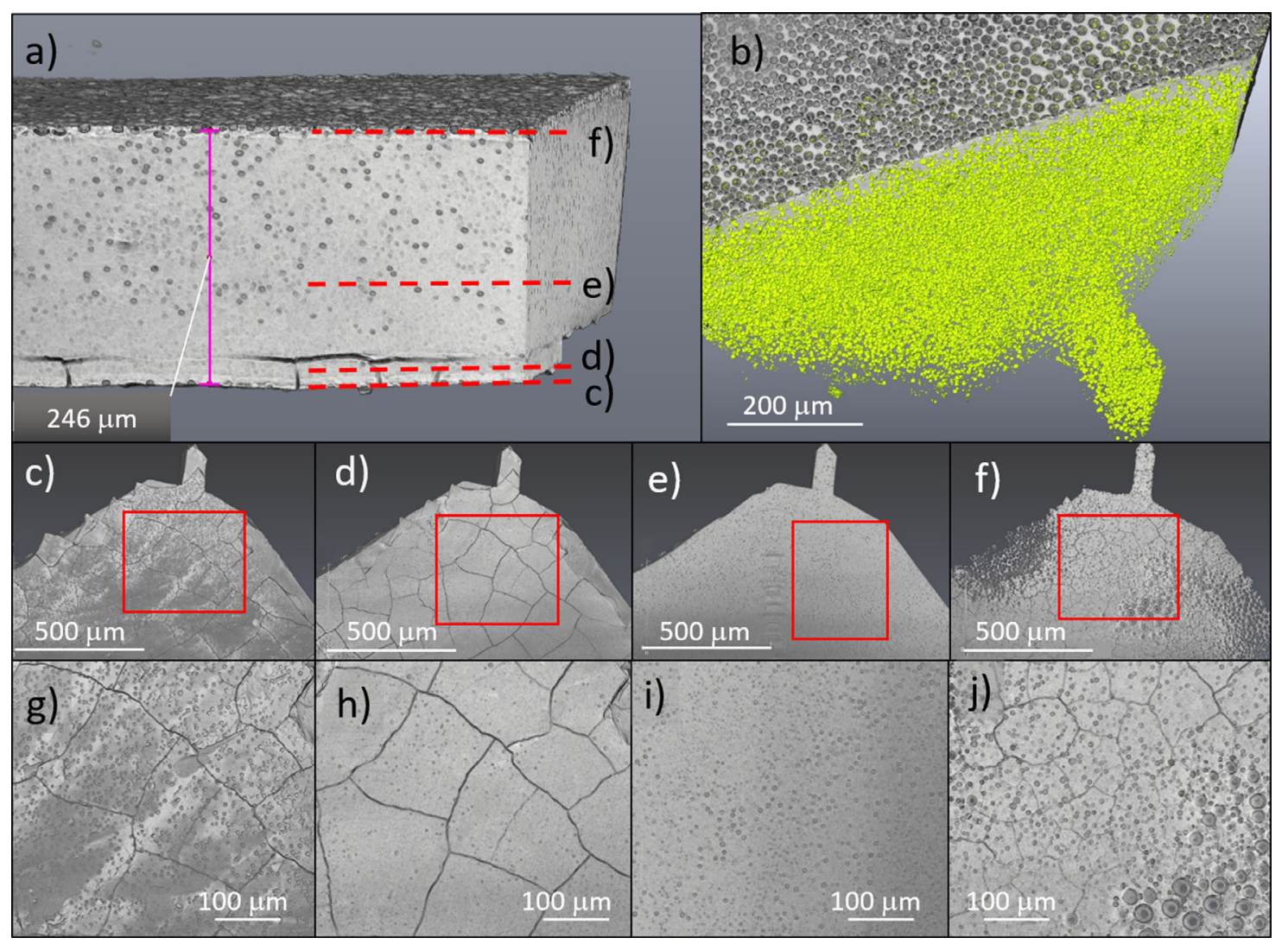

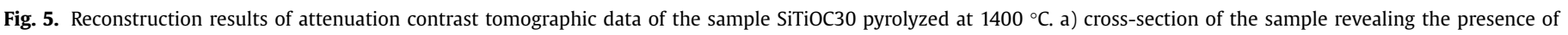

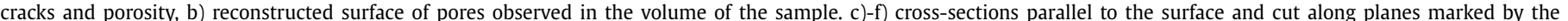

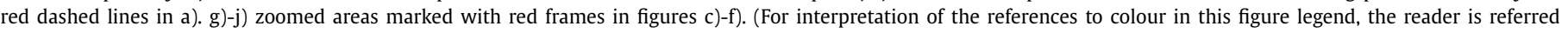
to the web version of this article.)

show zoomed areas marked in Fig. 5c)-f), respectively. These images show that the middle layer is free of cracks, while both outer layers suffer from significant cracking. Cracks in outer layers are oriented perpendicularly to the surface and change direction when reaching the interface to the middle layer propagating along this interface and causing delamination.

Fig. 6 shows the XRF (a) and XRD (b, c) mapping for the same sample as in Fig. 5, confirming segregation of Ti in the vicinity of surface (Fig. 6a)). XRD patterns (Fig. 6e)) evaluated for ROI4, ROI5 and ROI6 in Fig. 6d), show that the middle layer has the same crystallographic structure as for SiTiOC20 samples, however the $\mathrm{TiO}_{1-\mathrm{x}} \mathrm{C}_{\mathrm{x}}$ peaks are narrower. XRD map in Fig. 6b) shows that the highest intensity at the diffraction angle corresponding to $\mathrm{TiO}_{1-\mathrm{x}} \mathrm{C}_{\mathrm{x}}$ is observed in the top layer, though in case of the bottom layer it is still much more pronounced than in the middle layer. XRD patterns for regions at the surface (ROI1 and ROI9) show also presence of cristobalite $\mathrm{SiO}_{2}$ phase. A map of intensities collected at an angle corresponding to the cristobalite phase (Fig. 6b)) shows the strongest intensity in the bottom of layer. Powder diffraction patterns for this region revealed also the presence of a minor phase of $\mathrm{Ti}_{3} \mathrm{O}_{5}$. Analogous results were obtained for SiTiOC40 samples.

\subsection{Formation of phases during pyrolysis}

Fig. 7a) presents the results of the in-situ XRD measurements for SiTiOC20 considering the angular $2 \theta$ range between $11^{\circ}$ and $16^{\circ}$ covering two most distinct peaks of $\mathrm{TiO}_{1-\mathrm{x}} \mathrm{C}_{\mathrm{x}}$. Fig. 7c) plots the dependence of the crystallite sizes calculated based on the Scherrer equation as a function of sintering time. The changes in crystallite size are pronounced when increasing the temperature, then flat- ten while holding the temperature for $30 \mathrm{~min}$. Ex-situ PD studies of samples SiTiOC20 pyrolyzed for $1 \mathrm{~h}$ (Fig. 7b)) still exhibit large peak broadening (crystallite size estimated from fitting (111) and (200) peaks is $8.5 \mathrm{~nm}$ ). These results support the observation that pyrolysis in sequential steps $\left(1200{ }^{\circ} \mathrm{C}, 1300{ }^{\circ} \mathrm{C}, 1400{ }^{\circ} \mathrm{C}\right)$ instead of one step at $1400{ }^{\circ} \mathrm{C}$, will not significantly affect the final crystallite sizes.

It should be noted that evaluation of crystallite sizes based on the Scherrer equation provides only a rough approximation since factors such as the geometry and size distribution of the crystallites, strain broadening and the Debye-Waller factor are not considered here. Broadening of $\mathrm{TiO}_{1-\mathrm{x}} \mathrm{C}_{\mathrm{x}}$ peaks will also be affected by the value of $x$. Nevertheless this is sufficient for this study, as in this case evaluation of relative sizes and their increase with time are of interest, which provides a reliable measure of the crystallization dynamics.

\subsection{Macroscopic properties}

\subsubsection{Effect of Ti content on electrical conductivity}

Fig. 8a) presents electrical conductivity measurements conducted using the four point probe method for samples with various Ti content and pyrolyzed at $1000{ }^{\circ} \mathrm{C}$ and $1400{ }^{\circ} \mathrm{C}$. For samples pyrolyzed at $1000{ }^{\circ} \mathrm{C}$, the conductivity increases with Ti content up to SiTiOC30, but further increase of Ti leads to a slight drop in conductivity (though within the error). The lack of a further increase with increasing $\mathrm{Ti}$ content is likely related to the different structure of the outer layers, as observed for SiTiOC40 (Fig 2d). For every Ti content, samples pyrolyzed at $1400{ }^{\circ} \mathrm{C}$ exhibit higher conductivities compared to low temperature counterparts, but with no 

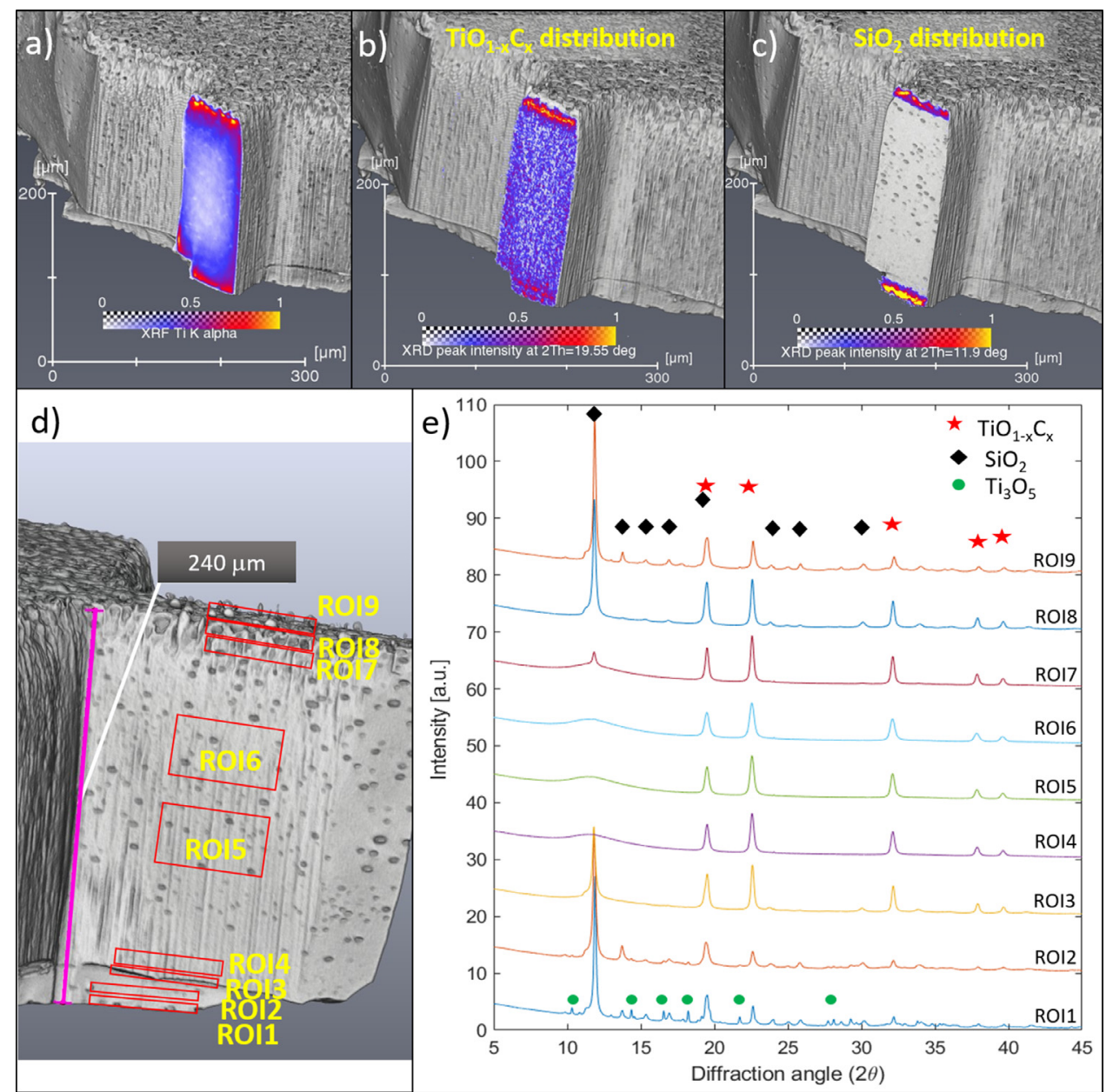

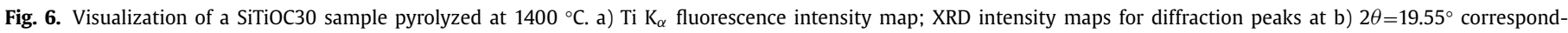

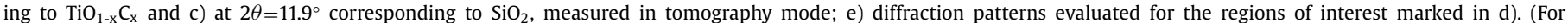
interpretation of the references to colour in this figure legend, the reader is referred to the web version of this article.)

significant dependence on the Ti content. An increase in ordering of free carbon network is one of the main expected reasons for the increase in conductivity at higher pyrolysis temperatures.

\subsubsection{Shrinkage of samples during pyrolysis}

Fig. 8b) shows results of thermomechanical analysis (TMA) performed during the pyrolysis process of samples with various amount of Ti. Expected significant shrinkage after $400{ }^{\circ} \mathrm{C}$ occurs due to removal of organic moieties during the polymer to ceramic transformation. The slight increase in dimension measured for the SiTiOC30 and SiTiOC40 samples after $1200{ }^{\circ} \mathrm{C}$ has to be related to the developing porosity.

\section{Discussion}

Tomography demonstrates that samples pyrolyzed at $1000{ }^{\circ} \mathrm{C}$ or $1400{ }^{\circ} \mathrm{C}$ with various Ti content exhibit a layered structure (oriented horizontally with respect to the sample substrate during pyrolysis). When pyrolyzed at $1000{ }^{\circ} \mathrm{C}$, samples are crack-free, but pyrolysis at $1400{ }^{\circ} \mathrm{C}$ results in formation of cracks and, for higher Ti content, also porosity. XRD and XRF imaging revealed that the observed layers differ in crystallographic structure and/or Ti concentration. Difference in Ti concentration is the main factor causing contrast in tomography in samples pyrolyzed at $1000^{\circ} \mathrm{C}$. Layers observed in samples pyrolyzed at $1400{ }^{\circ} \mathrm{C}$ differ significantly also in crystallographic structure.
The structure of the samples pyrolyzed at $1000{ }^{\circ} \mathrm{C}$ consists mainly of amorphous SiOC phase, with nanosized TiO rock salt phase precipitations, as witnessed by the XRD patterns. For the samples with highest amount of $\mathrm{Ti}$ (SiTiOC40), the nanocrystalline $\mathrm{TiO}_{2}$ rutile phase is observed near the surfaces, which is caused by larger amount of oxygen in the starting polymer precursor (revealed by elemental analysis). The presence of $\mathrm{TiO}_{2}$ explains decreased conductivity for SiTiOC40 samples with respect to SiTiOC30, as rutile has significantly lower electrical conductivity than values reported in this work (Fig. 8a)) [49].

The samples pyrolyzed at $1400{ }^{\circ} \mathrm{C}$ (SiTiOC20, SiTiOC30, SiTiOC40) have a similar structure in terms of crystallography. The middle layer contains amorphous $\mathrm{SiOC}$ and nanocrystalline $\mathrm{TiO}_{1-\mathrm{x}} \mathrm{C}_{\mathrm{x}}$. The outer layers show a more advanced crystallization of $\mathrm{TiO}_{1-\mathrm{x}} \mathrm{C}_{\mathrm{x}}$ with almost no amorphous phase, but instead the presence of $\beta$-SiC phase. Diffraction reflections of $\mathrm{TiO}_{1-\mathrm{x}} \mathrm{C}_{\mathrm{x}}$ and $\beta$-SiC appear very close to each other and it has been demonstrated that these phases can create a solid solution [36]. Therefore, the presence of $\beta$-SiC in the middle layer cannot be completely excluded, however, presence of the amorphous peak indicates that most of the $\mathrm{Si}$ atoms are in the amorphous phase and do not contribute to $\mathrm{TiO}_{1-\mathrm{x}} \mathrm{C}_{\mathrm{x}}$. This was supported by Rietveld refinement - based analysis performed on the patterns evaluated for the middle layer of the samples presented in Fig. 4. The best fitting was obtained for a model assuming $\mathrm{TiO}_{1-\mathrm{x}} \mathrm{C}_{\mathrm{x}}$ with $\mathrm{x}$ in the range of $0.8-0.9$ (structure close to pure $\mathrm{TiC}$ ), with the $\mathrm{Fm} 3-\mathrm{m}$ structure and no contribution 

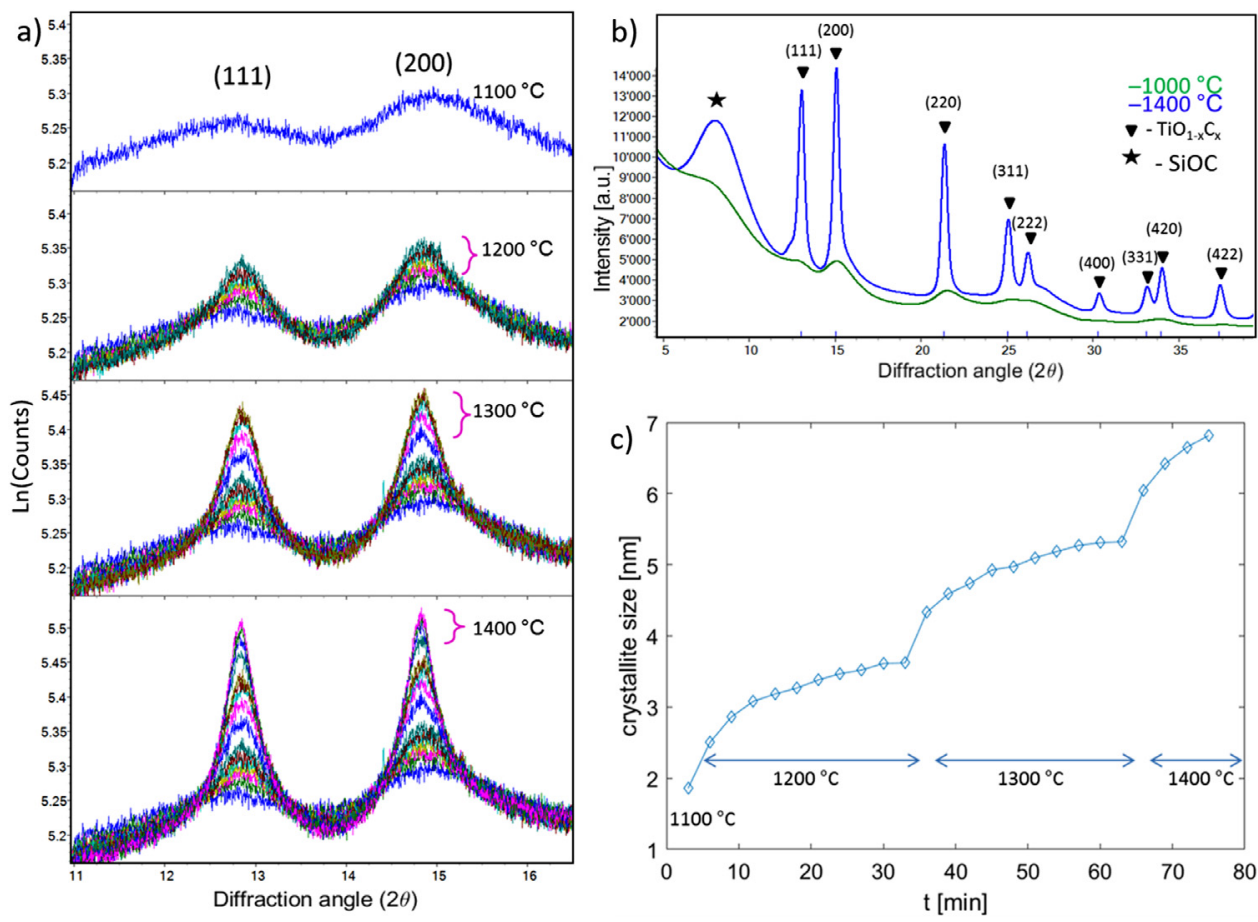

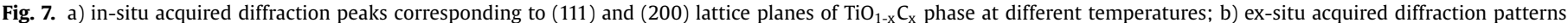

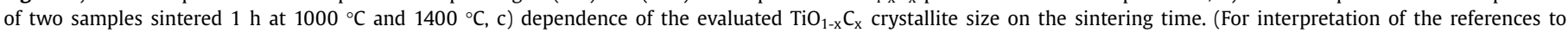
colour in this figure legend, the reader is referred to the web version of this article.)
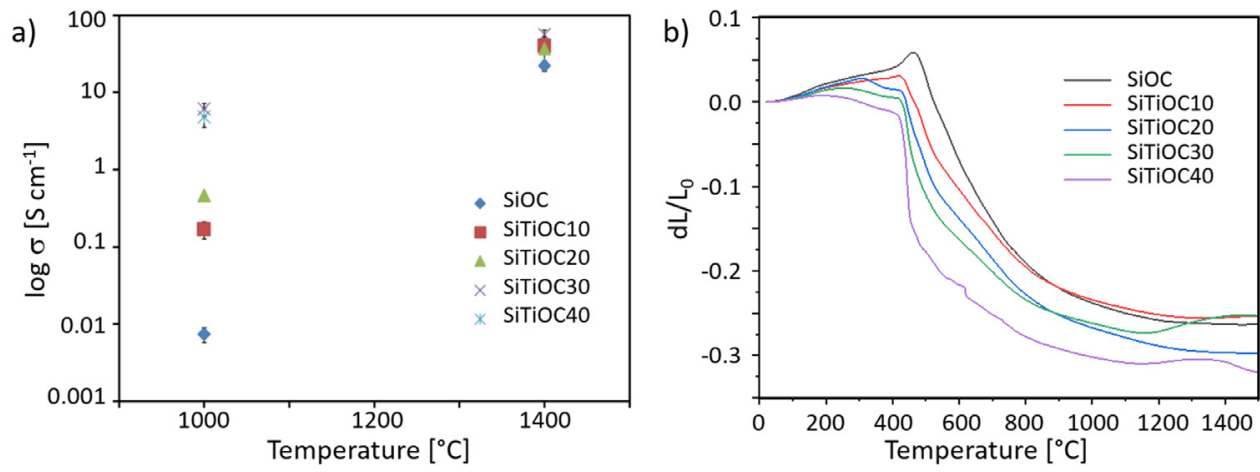

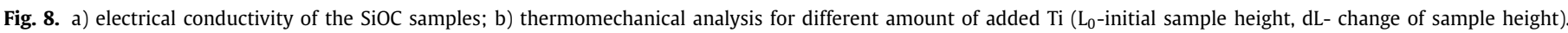

of $\mathrm{Si}$ and no presence of the $\beta$-SiC phase. Due to very similar values of the scattering factors of $\mathrm{O}$ and $\mathrm{C}$, the value of $\mathrm{x}$ cannot be determined with higher precision. At the outer layers, the diffraction peaks of $\mathrm{TiO}_{1-\mathrm{x}} \mathrm{C}_{\mathrm{x}}$ and $\beta$-SiC are split, demonstrating that the two phases are present and there is no solid solution. Remarkably, for all samples pyrolyzed at $1400{ }^{\circ} \mathrm{C}$, middle layers exhibit almost identical diffraction patterns for all ROIs within these layers indicating very homogenous structure, while the outer layers show gradual changes of crystallite sizes and amounts of $\mathrm{TiO}_{1-\mathrm{x}} \mathrm{C}_{\mathrm{x}}$ and $\beta$-SiC phases that vary along the normal to the layers and surface. Higher amounts of Ti resulted in more advanced crystallization (analysis of powder patterns shows larger crystallites) and the corresponding large amount of oxygen in the precursor polymer mixture led to creation of additional oxide phases on the surface: $\mathrm{SiO}_{2}\left(\alpha\right.$-cristobalite) and small amount of $\mathrm{Ti}_{3} \mathrm{O}_{5}$.

The presented results show that cracks appear only in outer layers, which exhibit more advanced crystallization and phase gradients, or at the interfaces between the layers. Different crystallographic structures have different mechanical properties and coefficients of thermal expansion (CTE), thus, cooling after the pyrolysis induces either tensile or compressive stresses in layers with higher and lower CTE, respectively.

$\mathrm{XRF}$ analysis shows a larger concentration of $\mathrm{Ti}$ in the outer layers, suggesting a higher fraction of $\mathrm{TiO}_{1-\mathrm{x}} \mathrm{C}_{\mathrm{x}}$ in outer layers where also $\beta$-SiC is observed. The elemental analysis performed for entire samples shows a decrease of the total amount of $C$ in samples at $1400{ }^{\circ} \mathrm{C}$. Since the formation of $\beta$-SiC trough carbothermal reduction is accompanied by free carbon consumption and $\mathrm{CO}$ gas production $[2,23]$, it can be concluded that more free $C$ was removed from outer layers containing $\beta$-SiC compared to the middle layer containing amorphous SiOC. More advanced crystallization of $\mathrm{TiO}_{1-\mathrm{x}} \mathrm{C}_{\mathrm{x}}$ (with $\mathrm{x}$ close to 1 ) in outer layers is expected to have a similar effect on the carbon content in various layers. Removal of $\mathrm{C}$ and $\mathrm{O}$ in outer layers results in higher concentration of $\mathrm{Ti}$, as it is observed in XRF mapping.

Typical CTE values reported for amorphous SiOC are about $3 \times 10^{-6} / \mathrm{K}$ [50], for $\beta$-SiC $4 \times 10^{-6} / \mathrm{K}$ [51] and for TiC with Fm3-m structure between $7 \times 10^{-6} / \mathrm{K}$ and $8.5 \times 10^{-6} / \mathrm{K}[52,53]$. Therefore, CTE of the outer layers with higher fraction of $\mathrm{TiO}_{1-\mathrm{x}} \mathrm{C}_{\mathrm{x}}$ (which is close to $\mathrm{TiC}$ ) and $\beta$-SiC is expected to be higher than for 
the middle layers composed of amorphous SiOC, nanocrystalline $\mathrm{TiO}_{1-\mathrm{x}} \mathrm{C}_{\mathrm{x}}$ and containing larger amount of free carbon. This would result in tensile stress in outer layers and compressive in middle layer. Moreover, lower amount of free carbon in the outer layers increases stiffness and therefore brittleness of the material. Difference in CTE and free carbon content explains formation of cracks observed in Fig. 3d)-e), in which cracks propagate over large distances in direction parallel to the surface only within one outer layer, but do not propagate to the other layers.

Morphology of samples with thin outer layers, as observed in Fig. 3a)-c), reveals that surface-connected defects accelerate the crystallization process. The fact that these defects are surrounded by the phase observed in the outer layer, shows that the crystallization occurs easier in regions in contact to the local atmosphere, as this crystallization must be accompanied with release of carbon and oxygen to the atmosphere. This is in agreement with observations at micron-scale presented in [21].

The observed differences in structure and related material properties are more significant for higher Ti content. Therefore, also differences in CTE and mechanical strength should be larger, which explains the stronger warping of the samples and enhanced cracking in the outer layers observed for higher Ti content.

Elemental analysis has shown that higher amount of added $\mathrm{Ti}$ (SiTiOC40) is accompanied by significantly higher oxygen content in the final ceramic, which leads to further changes in structure and morphology in samples pyrolyzed at $1400{ }^{\circ} \mathrm{C}$. Up to $1200{ }^{\circ} \mathrm{C}$, the oxycarbide glasses usually exist as an amorphous matrix comprising $\mathrm{SiO}_{2}$ or SiOC phase along with a free carbon phase. At higher pyrolysis temperature, a process of carbothermal reduction starts with formation of $\mathrm{CO}, \mathrm{CO}_{2}$ gasses [13,21,23], which in the studied composition is attributed to the process of reaction between segregated oxygen-rich phases of both $\mathrm{Ti}$ and $\mathrm{Si}$ and the free carbon phase. Increased oxygen content results in excessive gas formation, which explains the porosity appearing for SiTiOC30 and SiTiOC40 samples. The creation of porosity is also accompanied by an increase of sample dimensions as observed in TMA measurements after $1200{ }^{\circ} \mathrm{C}$ for SiTiOC30 and SiTiOC40 samples (Fig. 8b)). High oxygen content in these samples also leads to creation of additional phases on the surface ( $\alpha$-cristobalite and $\mathrm{Ti}_{3} \mathrm{O}_{5}$ ).

\section{Conclusion}

Synchrotron tomographic microscopy combined with XRF- and XRD-contrast microscopy provided spatially resolved information about crack formation, elemental and structural phase distribution in PDC samples with different Ti content with resolution of $1 \mu \mathrm{m}$. The most important observations are:

- All the Ti modified PDC samples produced using a molding technique have a layer-wise structure.

- Samples pyrolyzed at $1000{ }^{\circ} \mathrm{C}$ with various amounts of Ti are crack-free, have a three layer structure with a higher concentration of $\mathrm{Ti}$ in the outer layers and depletion in the middle layer.

- Samples pyrolyzed at $1400{ }^{\circ} \mathrm{C}$ are composed of a middle layer containing amorphous $\mathrm{SiOC}$ and nanocrystalline $\mathrm{TiO}_{1-\mathrm{x}} \mathrm{C}_{\mathrm{x}}$ and outer layers composed of $\mathrm{TiO}_{1-\mathrm{x}} \mathrm{C}_{\mathrm{x}}$ and $\beta$-SiC with almost no amorphous phase. Crystallization of $\mathrm{TiO}_{1-\mathrm{x}} \mathrm{C}_{\mathrm{x}}$ in outer layers is more advanced than in middle layers. All samples suffer from cracks appearing in the outer layers and at the interface with the middle layer, where significant gradients of crystallographic phases are observed.

- Higher amount of added Ti (above $30 \mathrm{wt} \%$ of the Ti precursor in the starting mixture) in samples pyrolyzed at $1400{ }^{\circ} \mathrm{C}$ results in spherical porosity of about $4 \%$ homogenously distributed in the volume of the PDC samples and in the formation of Ti- and Si- oxides on the surface.

- Increasing Ti content enhances the electrical conductivity in samples pyrolyzed at $1000{ }^{\circ} \mathrm{C}$. Pyrolysis at $1400{ }^{\circ} \mathrm{C}$ lead to further increase of conductivity as compared with $1000{ }^{\circ} \mathrm{C}$, but with no dependence on Ti content.

Pyrolysis temperature plays a key role in determining many of the properties of PDC ceramics. The highest electrical conductivity was achieved for samples pyrolyzed at $1400{ }^{\circ} \mathrm{C}$, however such high temperature leads to creation of defects causing potentially mechanical failure. The best trade-off between structure and conductivity is obtained for samples with the highest used Ti amount and pyrolysed at $1000{ }^{\circ} \mathrm{C}$.

\section{Declaration of Competing Interest}

The authors declare that they have no known competing financial interests or personal relationships that could have appeared to influence the work reported in this paper.

\section{Acknowledgments}

This work was supported by Strategic Focus Area (SFA) - Advanced Manufacturing for the Ceramic X.0 - High-precision micromanufacturing of ceramics. We would like to acknowledge the Paul Scherrer Institut, Villigen, Switzerland for provision of synchrotron radiation beamtime at the TOMCAT, MS and microXAS beamlines of the Swiss Light Source. Furthermore, we want to acknowledge the use of plasma-FIB for sample preparation at ScopeM (the Scientific center for electron and optical Microscopy) at ETH Zürich and Joakim Reuteler for his support in using the plasma-FIB.

\section{Supplementary materials}

Supplementary material associated with this article can be found, in the online version, at doi:10.1016/j.actamat.2020.07.067.

\section{References}

[1] G. Mera, E. Ionescu, Polymer-Derived Ceramics, in: Encyclopedia Inorganic Bioinorganic Chem., John Wiley \& Sons, Ltd, Chichester, UK, 2019, pp. 1-26. https://doi.org/10.1002/9781119951438.eibc2705.

[2] Q. Wen, Z. Yu, R. Riedel, The fate and role of in situ formed carbon in polymerderived ceramics, Prog. Mater. Sci. 109 (2020) 100623 https://doi.org/10.1016/ j.pmatsci.2019.100623.

[3] P. Colombo, G. Mera, R. Riedel, G.D. Sorarù, Polymer-derived ceramics: 40 Years of research and innovation in advanced ceramics, J, Am. Ceram. Soc. 93 (2010) 1805-1837 https://doi.org/10.1111/j.1551-2916.2010.03876.x.

[4] K. Lu, Porous and high surface area silicon oxycarbide-based materials - A review, Mater. Sci. Eng. R Rep. 97 (2015) 23-49 https://doi.org/10.1016/j.mser. 2015.09.001.

[5] K. Lu, D. Erb, Polymer derived silicon oxycarbide-based coatings, Int. Mater. Rev. 63 (2018) 139-161 https://doi.org/10.1080/09506608.2017.1322247.

[6] N.M. Larson, F.W. Zok, In-situ 3D visualization of composite microstructure during polymer-to-ceramic conversion, Acta Mater. 144 (2018) 579-589 https: //doi.org/10.1016/j.actamat.2017.10.054.

[7] L.M. Reinold, M. Graczyk-Zajac, Y. Gao, G. Mera, R. Riedel, Carbon-rich SiCN ceramics as high capacity/high stability anode material for lithium-ion batteries, J, Power Sources 236 (2013) 224-229 https://doi.org/10.1016/j.jpowsour.2013. 02.046.

[8] M. Graczyk-Zajac, L. Toma, C. Fasel, R Riedel, Carbon-rich SiOC anodes for lithium-ion batteries: part I. Influence of material UV-pre-treatment on high power properties, in: Solid State Ionics, 2012, pp. 522-526. https://doi.org/10. 1016/j.ssi.2011.12.007.

[9] H. Fukui, H. Ohsuka, T. Hino, K. Kanamura, A Si-O-C composite anode: high capability and proposed mechanism of lithium storage associated with microstructural characteristics, ACS Appl. Mater. Interfaces 2 (2010) 999-1008 https://doi.org/10.1021/am100030f.

[10] R.J. -C. Dubey, P.V.W. Sasikumar, F. Krumeich, G. Blugan, J. Kuebler, K.V. Kravchyk, T. Graule, M.V. Kovalenko, Silicon Oxycarbide-Tin Nanocomposite as a High-Power-Density Anode for Li-Ion Batteries, Adv. Sci. 6 (2019) 1901220 https://doi.org/10.1002/advs.201901220. 
[11] A. Lale, A. Wasan, R. Kumar, P. Miele, U.B. Demirci, S. Bernard, Organosilicon polymer-derived mesoporous 3D silicon carbide, carbonitride and nitride structures as platinum supports for hydrogen generation by hydrolysis of sodium borohydride, Int. J. Hydrog. Energy 41 (2016) 15477-15488 https: //doi.org/10.1016/j.ijhydene.2016.06.186.

[12] X. Liu, Y.-.L. Li, F. Hou, Fabrication of SiOC Ceramic Microparts and Patterned Structures from Polysiloxanes via Liquid Cast and Pyrolysis, J, Am. Ceram. Soc. 92 (2009) 49-53 https://doi.org/10.1111/j.1551-2916.2008.02849.x.

[13] P.V.W. Sasikumar, G. Blugan, N. Casati, E. Kakkava, G. Panusa, D. Psaltis, J. Kuebler, Polymer derived silicon oxycarbide ceramic monoliths: microstructure development and associated materials properties, Ceram. Int. (2018) https: //doi.org/10.1016/j.ceramint.2018.08.102.

[14] Z.C. Eckel, C. Zhou, J.H. Martin, A.J. Jacobsen, W.B. Carter, T.A. Schaedler, Additive manufacturing of polymer-derived ceramics, Science (80-.). 351 (2016) 58-62 https://doi.org/10.1126/science.aad2688.

[15] E. Zanchetta, M. Cattaldo, G. Franchin, M. Schwentenwein, J. Homa, G. Brusatin, P. Colombo, Stereolithography of SiOC ceramic microcomponents, Adv. Mater. 28 (2016) 370-376 https://doi.org/10.1002/adma.201503470.

[16] S.A. Brinckmann, N. Patra, J. Yao, T.H. Ware, C.P. Frick, R.S. Fertig, Stereolithography of SiOC polymer-derived ceramics filled with SiC micronwhiskers, Adv. Eng. Mater. 20 (2018) 1800593 https://doi.org/10.1002/adem.201800593.

[17] L. Brigo, J.E.M. Schmidt, A. Gandin, N. Michieli, P. Colombo, G. Brusatin, 3D Nanofabrication of SiOC Ceramic Structures, Adv. Sci. (2018) 5 https://doi.org/ 10.1002/advs.201800937.

[18] J. Bauer, C. Crook, A. Guell Izard, Z.C. Eckel, N. Ruvalcaba, T.A. Schaedler, L. Valdevit, Additive manufacturing of ductile, ultrastrong polymer-derived nanoceramics, Matter 1 (2019) 1547-1556 https://doi.org/10.1016/j.matt.2019. 09.009.

[19] A. Ostendorf, B.N. Chichkov, L.Z. Hannover, Two-photon polymerization: a new approach to micromachining femtosecond lasers enable microfabrication with resolution beyond the diffraction limit., (2006).

[20] G. Konstantinou, E. Kakkava, L. Hagelüken, P.V. Warriam Sasikumar, J. Wang, M.G. Makowska, G. Blugan, N. Nianias, F. Marone, H. Van Swygenhoven, J. Brugger, D. Psaltis, C. Moser, Additive micro-manufacturing of crackfree PDCs by two-photon polymerization of a single, low-shrinkage preceramic resin, Addit. Manuf. (2020) 101343 https://doi.org/10.1016/j.addma.2020. 101343.

[21] D.L. Poerschke, A. Braithwaite, D. Park, F. Lauten, Crystallization behavior of polymer-derived Si-O-C for ceramic matrix composite processing, Acta Mater. 147 (2018) 329-341 https://doi.org/10.1016/j.actamat.2018.01.052.

[22] P. Vallachira Warriam Sasikumar, E. Mueller, P. Clement, J. Jang, E. kakkava, G. Panusa, D. Psaltis, K. Maniura-Weber, M. Rottmar, J. Brugger, G. Blugan, In vitro cytocompatibility assessment of Ti-modified silicon-oxycarbide based polymer-derived ceramic implantable electrodes under pacing conditions, ACS Appl. Mater. Interfaces (2020) https://doi.org/10.1021/acsami.0c01465.

[23] A. Saha, R. Raj, Crystallization maps for SiCO amorphous ceramics, J. Am. Ceram. Soc. 90 (2007) 578-583 https://doi.org/10.1111/j.1551-2916.2006.01423.x.

[24] C. Stabler, F. Celarie, T. Rouxel, R. Limbach, L. Wondraczek, R. Riedel, E. Ionescu, Effect of composition and high-temperature annealing on the local deformation behavior of silicon oxycarbides, J. Eur. Ceram. Soc. 39 (2019) 2287-2296 https://doi.org/10.1016/j.jeurceramsoc.2019.02.024.

[25] R. Kumar, Y. Cai, P. Gerstel, G. Rixecker, F. Aldinger, Processing, crystallization and characterization of polymer derived nano-crystalline Si-B-C-N ceramics, in: Journal of Materials Science, Springer, 2006, pp. 7088-7095. https: //doi.org/10.1007/s10853-006-0934-6.

[26] G.D. Sorarù, A. Glisenti, G. Granozzi, F. Babonneau, J.D. Mackenzie, The pyrolysis process of a polytitanocarbosilane into SiC/TiC ceramics: an XPS study, J. Mater. Res. 5 (1990) 1958-1962 https://doi.org/10.1557/JMR.1990.1958.

[27] F. Babonneau, G.D. Sorarù, J.D. Mackenzie, 29Si MAS-NMR investigation of the conversion process of a polytitanocarbosilane into SiC-TiC ceramics, J. Mater. Sci. 25 (1990) 3664-3670 https://doi.org/10.1007/BF00575402.

[28] G. Neumann, R. Kieffer, P. Ettmayer, Über das system TiC-TiN-TiO, Monatsh. Chem. 103 (1972) 1130-1137 https://doi.org/10.1007/BF00905189.

[29] B. Jiang, N. Hou, S. Huang, G. Zhou, J. Hou, Z. Cao, H. Zhu, Structural studies of TiC1-xOx solid solution by Rietveld refinement and first-principles calculations, J. Solid State Chem. 204 (2013) 1-8 https://doi.org/10.1016/J.JSSC.2013. 05.009 .

[30] D.N. Miller, A.K. Azad, H. Delpouve, L. Quazuguel, J. Zhou, A. Sinha, P. Wormald, J.T.S. Irvine, Studies on the crystal structure, magnetic and conductivity properties of titanium oxycarbide solid solution $\left(\mathrm{TiO}_{1-\mathrm{x}} \mathrm{C}_{\mathrm{x}}\right)$. J. Mater. Chem. A. 4 (2016) 5730-5736 https://doi.org/10.1039/C6TA00042H.

[31] F. Réjasse, O. Rapaud, J. Léchelle, G. Trolliard, H. Khodja, O. Masson, G. Martin, A. Maître, Novel insight into the chemical analysis of light elements in oxycarbides, Acta Mater. 157 (2018) 11-20 https://doi.org/10.1016/j.actamat.2018. 07.023

[32] F. Réjasse, G. Trolliard, J. Léchelle, O. Rapaud, P. Carles, O. Grauby, H. Khodja, Study of the TiC1-X - TiO2 reactive interface, Acta Mater. 146 (2018) 225-236 https://doi.org/10.1016/j.actamat.2017.12.055.
[33] A.C. Fernandes, F. Vaz, L. Rebouta, A. Pinto, E. Alves, N.M.G. Parreira P. Goudeau, E. Le Bourhis, J.P. Rivière, Influence of the $\mathrm{O} / \mathrm{C}$ ratio in the behaviour of TiCxOy thin films, Surf. Coatings Technol. 201 (2007) 5587-5591 https://doi.org/10.1016/j.surfcoat.2006.07.133

[34] N.R. Mediukh, V.I. Ivashchenko, D.A. Pogrebnjak, V.I. Shevchenko, First-principles study of thermodynamic and stability properties of TiC-SiC alloys, in Proc. 6th Int. Conf. Nanomater. Appl. Prop. N. 2016, Institute of Electrical and Electronics Engineers Inc., 2016.

[35] H. Endo, M. Ueki, H. Kubo, Microstructure and mechanical properties of hotpressed SiC-TiC composites, J. Mater. Sci. 26 (1991) 3769-3774 https://doi.org/ 10.1007/BF01184969.

[36] N.R. Mediukh, V.I. Ivashchenko, P.E.A. Turchi, V.I. Shevchenko, J. Leszczynski, L. Gorb, Phase diagrams and mechanical properties of TiC-SiC solid solutions from first-principles, Calphad Comput. Coupl. Phase Diagr. Thermochem. 66 (2019) 101643 https://doi.org/10.1016/j.calphad.2019.101643.

[37] N.M. Larson, C. Cuellar, F.W. Zok, X-ray computed tomography of microstructure evolution during matrix impregnation and curing in unidirectional fiber beds, Compos. Part A. 117 (2019) 243-259 https://doi.org/10.1016/j. compositesa.2018.11.021.

[38] G. Lovric, R. Mokso, C.M. Schlepütz, M. Stampanoni, A multi-purpose imaging endstation for high-resolution micrometer-scaled sub-second tomography, Phys. Med. 32 (2016) 1771-1778 https://doi.org/10.1016/j.ejmp.2016.08.012.

[39] F. Marone, A. Studer, H. Billich, L. Sala, M. Stampanoni, Towards on-the-fly data post-processing for real-time tomographic imaging at TOMCAT, Adv. Struct. Chem. Imaging. 3 (2017) 1 https://doi.org/10.1186/s40679-016-0035-9.

[40] F. Marone, M. Stampanoni, Regridding reconstruction algorithm for real-time tomographic imaging, J. Synchrotron Radiat 19 (2012) 1029-1037 https://doi. org/10.1107/S0909049512032864.

[41] 3D Visualization $\mathcal{E}$ Analysis Software | Thermo Fisher Scientific - CH. (n.d.). Retrieved August 10, 2020, from https://www.thermofisher.com/ ch/en/home/industrial/electron-microscopy/electron-microscopy-instrumentsworkflow-solutions/3d-visualization-analysis-software.html.

[42] C.N. Borca, D. Grolimund, M. Willimann, B. Meyer, K. Jefimovs, J. VilaComamala, C. David, The microXAS beamline at the swiss light source: towards nano-scale imaging, J. Phys. Conf. Ser. 186 (2009) 012003 https://doi. org/10.1088/1742-6596/186/1/012003.

[43] D.F. Sanchez, D. Grolimund, M. Hubert, P. Bleuet, J. Laurencin, A 2D and 3D X-ray $\mu$-diffraction and $\mu$-fluorescence study of a mixed ionic electronic conductor, Int. J. Hydrog. Energy. 42 (2017) 1203-1211 https://doi.org/10.1016/J IJHYDENE.2016.11.094.

[44] P.R. Willmott, D. Meister, S.J. Leake, M. Lange, A. Bergamaschi, M. Böge, M. Calvi, C. Cancellieri, N. Casati, A. Cervellino, Q. Chen, C. David, U. Flechsig, F. Gozzo, B. Henrich, S. Jäggi-Spielmann, B. Jakob, I. Kalichava, P. Karvinen, J. Krempasky, A. Lüdeke, R. Lüscher, S. Maag, C. Quitmann, M.L. ReinleSchmitt, T. Schmidt, B. Schmitt, A. Streun, I. Vartiainen, M. Vitins, X. Wang R. Wullschleger, The materials science beamline upgrade at the swiss light source, J. Synchrotron Radiat. 20 (2013) 667-682 https://doi.org/10.1107/ S0909049513018475.

[45] A. Bergamaschi, A. Cervellino, R. Dinapoli, F. Gozzo, B. Henrich, I. Johnson, P. Kraft, A. Mozzanica, B. Schmitt, X. Shi, IUCr, The MYTHEN detector for Xray powder diffraction experiments at the Swiss Light Source, J. Synchrotron Radiat. 17 (2010) 653-668 https://doi.org/10.1107/S0909049510026051.

[46] DIFFRAC.SUITE TOPAS - XRD Software, X-ray diffraction - XRD Software | Bruker (n.d.). Retrieved August 10, 2020, from https://www.bruker.com/products/ $\mathrm{x}$-ray-diffraction-and-elemental-analysis/x-ray-diffraction/xrd-software/topas. html.

[47] V.V. Pujar, J.D. Cawley, Effect of Stacking Faults on the X-ray Diffraction Profiles of beta-SiC Powders, J. Am. Ceram. Soc. 78 (1995) 774-782 https://doi.org/10 1111/j.1151-2916.1995.tb08246.x.

[48] D.-.H. Wang, D. Xu, Q. Wang, Y.-.J. Hao, G.-.Q. Jin, X.-.Y. Guo, K.N. Tu, Periodically twinned SiC nanowires, Nanotechnology 19 (2008) 215602 https: //doi.org/10.1088/0957-4484/19/21/215602.

[49] C. Demetry, X. Shi, Grain size-dependent electrical properties of rutile (TiO2) Solid State Ionics 118 (1999) 271-279 https://doi.org/10.1016/s0167-2738(98) 00454-8.

[50] C. Stabler, A. Reitz, P. Stein, B. Albert, R. Riedel, E. Ionescu, Thermal properties of SiOC glasses and glass ceramics at elevated temperatures, Mater. (Basel) 11 (2018) 279 https://doi.org/10.3390/ma11020279.

[51] D.N. Talwar, J.C. Sherbondy, Thermal expansion coefficient of 3C-SiC, Appl. Phys. Lett. 67 (1995) 3301 https://doi.org/10.1063/1.115227.

[52] G.M. Song, Y. Zhou, S.J.L. Kang, D.Y. Yoon, Effect of carbon fibers on the thermophysical properties of TiC composites, J. Mater. Sci. Lett. 21 (2002) 17331736 https://doi.org/10.1023/A:1020948132154.

[53] C.J. Engberg, E.H. Zehms, Thermal expansion of Al2O3, BeO, MgO, B4C, SiC and TiC above 1000oC., J. Am. Ceram. Soc. 42 (1959) 300-305 https://doi.org/ 10.1111/j.1151-2916.1959.tb12958.x. 